\title{
The Relationship Between Football Participation Level and Lower Leg Alignment in Youth Males: Genu Varum
}

\author{
Tuba Melekoğlu ${ }^{1}$, Ali Işın ${ }^{1}$ \\ ${ }^{1}$ Faculty of Sports Sciences, Akdeniz University, Antalya, Turkey \\ Correspondence: Ali Işın, Faculty of Sports Sciences, Akdeniz University, Antalya, Turkey.
}

Received: November 22, 2018

Accepted: December 28, 2018

Online Published: January 8, 2019

doi:10.11114/jets.v7i2.3955

URL: https://doi.org/10.11114/jets.v7i2.3955

\begin{abstract}
The aim of this study was to determine the effects of football participation levels on genu varum ratings by using Q angle and intercondylar distance. Twenty male football players for each elite and amateur football teams and 20 sedentary young male volunteers participated in this study. The anthropometric variables (body height, body weight, body fat percentage, body mass index) and genu varum levels by evaluating the lower extremity alignment using intercondylar distance, and Q angles for both legs were measured. The intercondylar distance measurements were done by using caliper with the sensitivity of $0.01 \mathrm{~mm}$ and $\mathrm{Q}$ angle measurements were carried out by the examination of the photographs of participants. One Way ANOVA and post-hoc Tukey test were used to assess statistically intra-group differences. Cohen's Kappa coefficient were used to determine agreement among observers. SPSS v.25 program was used to analyse the data. Intercondylar distance values were found significantly higher in elite group than in amateur and sedentary groups $(45.65 \pm 13.54 ; 28.84 \pm 14.61 ; 3.70 \pm 5.19 \mathrm{~mm}$, respectively, $\mathrm{p}<0.001)$. As a result of this study, it was determined that the participation level of football trainings lead an increase in intercondylar distance significantly. The highest Q-angle values were observed in amateur football players.
\end{abstract}

Keywords: genu varum, leg alignment, intercondylar distance, Q angle

\section{Introduction}

Football can be mentioned as a lower extremity-dominant sport due to the control of ball mainly with foot, ankle and leg movements (Espregueira-Mendes et al., 2017). Thus, football injuries are mostly occurred in lower extremity, particularly knees and ankles (Dvorak \& Junge, 2000). There are three main factors contributing to increased risk of knee injury in football which are player's age, previous history of injury and knee alignment. The most common injuries associated with knee in football are patellofemoral pain syndrome (PFPS) and anterior cruciate ligament injury (ACL) (Flandry \& Hommel, 2011; Ortiz \& Micheo, 2011). Genu varum is highly associated with ACL (Jan van de Pol, Arnold, Verdonschot, \& van Kampen, 2009) and PFPS (Lewek, Rudolph, \& Snyder-Mackler, 2004).

Genu varum is thought to be one of the angular deformities of knee and known as "Bowlegs". It increases distance among legs in the femoral condyles as well as changing tibiofemoral angle. This distance is known as intercondylar distance. It is one of the most common anatomical variations of alignment in musculoskeletal system (Cheema, Grissom, \& Harcke, 2003). Genu varum influences factors such as age, body weight, vitamin/hormone intake, nutrition, environment and training. Moreover, incidence and degree of genu varum may also vary according to ethnic factors (Cheng, Chan, Chiang, \& Hui, 1991).

Researches investigating sports participation and genu varum mostly focused on football and high correlation was determined between genu varum and football participation (Thijs, Bellemans, Rombaut, \& Witvrouw, 2012). It is reported that frequency and degree of genu varum is higher in football players than sedentary (Colyn, Arnout, Verhaar, \& Bellemans, 2016). Regular football training exposes the knee joint to load and torque pressures that contribute to genu varum in lower extremity. In some studies, genu varum has been reported to increase risk of injury and thus, development of genu varum should be reduced (Brouwer et al., 2007; Espandar, Mortazavi, \& Baghdadi, 2010). Considering millions of children participate in high-level football training, it is highly essential to investigate relationship between genu varum and football participation (Witvrouw, Danneels, Thijs, Cambier, \& Bellemans, 2009). The aim of this study was to determine the effects of football participation levels on genu varum ratings by using $\mathrm{Q}$ angle and intercondylar distance. 


\section{Method}

The body height was measured using stadiometer (SECA 213, Germany), body weight and body fat percentage were measured using a bioelectrical impedance device (Tanita SC 330, Japan). Body mass index was calculated using $\mathrm{kg} / \mathrm{m} 2$ formula. Intercondylar distance (ICD), right knee Q angle (RKQ) and left knee Q angle (LKQ) values were measured in order to calculate genu varum values.

\subsection{Subjects}

Forty football players playing football at different levels and 20 non-athletes voluntarily participated in the study. Participants were divided into three groups as elite football group (EFG; n: 20), amateur football group (AFG; n: 20) and non-athlete group (NG; n: 20). EFG consists of football players participating in higher level of football training for at least 5 years (at least 5 days/week), AFG consists of football players participating in moderate level football training for at least 5 years (at least 3 days/week) and NG consist of non-athletes who did not participate in any regular sports training.

\subsection{Intercondylar Distance (ICD) Measurement}

Intercondylar Distance (ICD) measurement was measured using a caliper with a precision of $0.01 \mathrm{~mm}$. The volunteers were asked to bring their hip, knee and ankles and medial tibial malleolus or medial femoral condyles as close as possible without any forced muscle contractions (Rezende, Santos, Araújo, \& Matsudo, 2011). Measurements were taken on a flat floor and barefoot (Cheng et al., 1991).

\subsection{Quadriceps Angle (Q Angle) Measurement}

Anterior superior iliac spine (ASIS), tibial tubercle and mid-point of patella of both limbs were found palpating and were marked with small round dot stickers (Cowan et al., 1996). Volunteers were asked to avoid quadriceps muscle constriction, which is a factor that may cause a decrease in Q angle while standing. A digital camera (Nikon D7000, Tokyo, Japan) was used to take a photo. Digital camera was located three meters away from participations (Braz, Goes, \& Carvalho, 2017; Ruivo, Pezarat-Correia, Carita, \& Vaz, 2013).

Lines were drawn between the marks placed on the ASIS and mid-point of patella and tibial tubercle, angle of intersection of these lines was then measured using computer program (Optojump Next, Microgate, Bolzano, Italy) (Figure 1.). Right knee $\mathrm{Q}$ angle (RKQ) and left angle $\mathrm{Q}$ angle (LKQ) of volunteers were measured and evaluated separately (Lathinghouse \& Trimble, 2000; Rossi, Bruzzone, Dettoni, \& Margheritini, 2011).

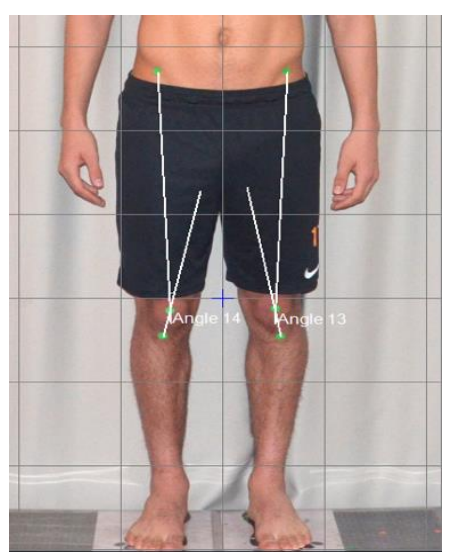

Figure 1. Measurement of Q angle

\subsection{Statistical Analysis}

Level of skewness and kurtosis of data were examined (Tabachnick \& Fidell, 2013), Shapiro-Wilk test (Shapiro \& Wilk, 1965), and Levene test which applied for homogeneity of variance were applied (Martin \& Bridgmon, 2012). One-way ANOVA was used to evaluate difference among 3 groups and Tukey post-hoc test was performed. Cohen's kappa test was used to determine inter-observer agreement (Cohen's kappa coefficient; .94). Data were analyzed using SPSS v.25 program and statistical significance was accepted at the level of $\mathrm{p}<0.05$.

\section{Results}

Demographic values of volunteers participating in this study are given in Table 1. Significant difference was not found between age, body height, body weight, body fat percentage and BMI values of participants ( $p>0.05$ ). 
Table 1. Demographic values of volunteers

\begin{tabular}{lccc}
\hline Variables & EFG & AFG & NG \\
N=20 & N=20 & N=20 \\
\hline Age & $17.34 \pm 0.31$ & $17.99 \pm 0.61$ & $17.66 \pm 0.47$ \\
Body Height & $178.00 \pm 7.32$ & $176.80 \pm 7.11$ & $177.65 \pm 4.17$ \\
Body Weight & $69.82 \pm 7.59$ & $66.97 \pm 7.76$ & $65.68 \pm 4.94$ \\
Body Fat (\%) & $11.48 \pm 2.33$ & $9.45 \pm 3.42$ & $9.85 \pm 3.41$ \\
BMI & $22.00 \pm 1.66$ & $21.45 \pm 2.55$ & $20.83 \pm 1.57$ \\
\hline
\end{tabular}

Body Fat \%: body fat percentage, BMI: body mass index, EFG: elite football group, AFG: amateur football group, NG: non-athlete group

When evaluation of genu varum among groups of football players participating in this research; in terms of ICD, EFG was significantly higher than AFG and NG (45.65 $\pm 13.54 \mathrm{~mm} ; 28.84 \pm 14.61 \mathrm{~mm} ; 3.70 \pm 5.19 \mathrm{~mm}$; respectively, p<001) and, in terms of RKQ and LKQ values, AFG was significantly higher than EFG and NG (p<001). Genu varum values of volunteers participating in the study are given in Table 2.

Table 2. Genu varum values of volunteers

\begin{tabular}{lccc}
\hline Variables & EFG & AFG & NG \\
& $\mathbf{N = 2 0}$ & $\mathbf{N = 2 0}$ & N=20 \\
\hline ICD $(\mathrm{mm})$ & $45.65 \pm 13.54^{\mathrm{a}, \mathrm{b}}$ & $28.84 \pm 14.61^{\mathrm{a}}$ & $3.70 \pm 5.19$ \\
RKQ $\left(^{\circ}\right)$ & $10.05 \pm 1.90^{\mathrm{b}}$ & $12.70 \pm 2.62^{\mathrm{a}}$ & $9.30 \pm 1.13$ \\
LKQ $\left(^{\circ}\right)$ & $10.00 \pm 1.86^{\mathrm{b}}$ & $12.70 \pm 2.34^{\mathrm{a}}$ & $9.30 \pm 1.22$ \\
\hline
\end{tabular}

ICD: Intercondylar distance, RKQ: right knee Q angle, LKQ: left knee Q angle, EFG: elite football group, AFG: amateur football group, NG: non-athlete group; differences compared to $\mathrm{NG:}{ }^{a}=\mathrm{p}<0.001$; differences compared to AFG: ${ }^{\mathrm{b}}=\mathrm{p}<0.001$

Table 3. ICD classifications of groups

\begin{tabular}{|c|c|c|c|c|}
\hline Groups & $\begin{array}{c}\text { Grade } 1 \\
(\mathrm{n} ; \%)\end{array}$ & $\begin{array}{c}\text { Grade } 2 \\
(\mathrm{n} ; \%)\end{array}$ & $\begin{array}{c}\text { Grade } 3 \\
(\mathrm{n} ; \%)\end{array}$ & $\begin{array}{c}\text { Grade } 4 \\
(\mathrm{n} ; \%)\end{array}$ \\
\hline EFG (N:20) & $1 ; \% 5$ & $10 ; \% 50$ & $9 ; \% 45$ & - \\
\hline AFG (N:20) & $9 ; \% 45$ & $9 ; \% 45$ & $2 ; \% 10$ & - \\
\hline NG (N:20) & $20 ; \% \mathbf{1 0 0}$ & - & - & - \\
\hline
\end{tabular}

ICD: Intercondylar distance, EFG: elite football group, AFG: amateur football group, NG: non-athlete group, Grade 1: 0-2,5 cm, Grade 2: 2,5-5 cm, Grade 3: $5-7,5 \mathrm{~cm}$, Grade 4: 7,5 $\leq \mathrm{cm}$

The incidence of genu varum among groups were shown in Table 3 according to the classification of ICD. There was no case in NG at Grade 2 and 3. However the cases in grade 2 and 3 increases with the participation level of football.

\section{Discussion}

Forty football players playing football at different levels and 20 non-athletes participated in the study, voluntarily. There were no significant differences in body height, body weight, body fat percentage and BMI of the three groups.

Although there is no definite information about normal values of Q angle, the values between 10 and 20 are widely used. Furthermore, different Q angle values have been reported in the studies (Rossi et al., 2011) and Q angle values above 15 for males and 20 for females are considered abnormal (Horton \& Hall, 1989). It is estimated that women and men have different Q-angles and this difference is due to the fact that women's pelvis are different compared to men (Kishali, İmamoglu, Burmaoglu, Atan, \& Yildirim, 2004). As a result of our research, when Q angle mean values of groups are examined; Q angle values were determined below 15 for all groups. When genu varum levels are examined according to $Q$ angle values, the incidence is $30 \%$ in amateur group, $5 \%$ in elite, and $0 \%$ in sedentary group. Moreover, in terms of RKQ and LKQ values, AFG was significantly higher than EFG and NG ( $<<001)$. It was found that EFG has higher ICD values than AFG and NG. Furthermore, the ICD values of AFG was statistically higher than NG ( $<<001)$. Similar to the results of our study, there are studies which revealed that football players have higher ICD than non-athletes. It was also reported that ICD increased with age and participation in training (Asadi et al., 2015; Işın, 2017; Rezende et al., 2011; Witvrouw et al., 2009).

There are different classification cut-points for ICD such as: $2 \mathrm{~cm}$ and above ((McDermott \& Freyne, 1983$), 4 \mathrm{~cm}$ and above (Park, Kong, Ko, Jang, \& Park, 2015) and $5 \mathrm{~cm}$ and above (Cahuzac, Vardon, \& Sales de Gauzy, 1995). Asadi et al. (2015) level of genu varum; Grade $1(0-2.5 \mathrm{~cm})$, Grade $2(2.5-5 \mathrm{~cm})$, Grade $3(5 \mathrm{~cm}-7.5 \mathrm{~cm})$ and Grade $4(7.5 \mathrm{~cm}$ and above) were evaluated at 4 levels. In our study, in terms of using the classification of Asadi et al. (2015), it was determined that the grades of ICD increase with the participation level of football training. As a result of a study comparing ICD in age groups of football players and non-athletes; the highest age of genu varum was reported to be between aged 16-18 years. (Asadi et al., 2015). Some studies were found that genu varum values increases starting from 
14 years and the highest vales were observed in 16-18 years (Işın, 2017; Thijs et al., 2012; Witvrouw et al., 2009).

The most performed activities in football are passes, running, cutting maneuvers, walking and kicking in elite and youth football players. To understand the relationship between genu varum and football, it is necessary to know the external load of the knee joint during different tasks in football (Witvrouw et al., 2009). Besier et al. (2001) investigated the external loading of the knee joint during cutting maneuvers and running and they found that valgus and varus stress on the knee joint was considerably increased during cutting maneuvers in comparison with running. Researchers have reported that inappropriate loading methods may adversely affect children in the development process (Bergeron et al., 2015; Faigenbaum, 2007). For this reason, regular participation in high-intensity physical activities has been found to cause genu varum (Chantraine, 1985; Thijs et al., 2012).

Researchers hypotheses that the increase of quadriceps muscle strength as a result of proper trainings tend to lead a correction of leg alignment. Correspondingly, it was reported that the strength training, which was started at an early age, affected the growth processes and leg alignment, positively (Bergeron et al., 2015; Faigenbaum, 2007).

On the other hand, it has been reported that the kicking actions specifically used in football is not only a simple knee extension and hip flexion, but also has a significant adduction component. Due to the fact that kicking is very common in football training and games, the adductor muscles of football players are expected to be strong. This situation in football players lead an imbalance between adductor and abductor muscle strength. That's why, it was mentioned that the stretching exercises to the contracted adductor muscles in young football players concomitantly technical and tactical training components is efficient (Witvrouw et al., 2009). The reason for the presence of genu varum in football players may be diagonal kicking action (Asadi et al., 2015).

As a result of this study, it was determined that the participation level of football trainings lead an increase in intercondylar distance significantly. The highest Q-angle values were observed in amateur football players.

\section{References}

Asadi, K., Mirbolook, A., Heidarzadeh, A., Kivi, M. M., Meybodi, M. K. E., \& Rad, M. R. (2015). Association of soccer and genu varum in adolescents. Trauma monthly, 20(2), e17184. https://doi.org/10.5812/traumamon.17184

Bergeron, M. F., Mountjoy, M., Armstrong, N., Chia, M., Côté, J., Emery, C. A., ... Léglise, M. (2015). International Olympic Committee consensus statement on youth athletic development. British journal of sports medicine, 49(13), 843-851. https://doi.org/10.1136/bjsports-2015-094962

Besier, T. F., Lloyd, D. G., Cochrane, J. L., \& Ackland, T. R. (2001). External loading of the knee joint during running and cutting maneuvers. Medicine and science in sports and exercise, 33(7), 1168-1175. https://doi.org/10.1097/00005768-200107000-00014

Braz, R. G., Goes, F. P. D. C., \& Carvalho, G. A. (2017). Confiabilidade e validade de medidas angulares por meio do software para avaliação postural. Fisioterapia em movimento, 21(3).

Brouwer, G., Tol, A. V., Bergink, A., Belo, J., Bernsen, R., Reijman, M., ... Bierma-Zeinstra, S. (2007). Association between valgus and varus alignment and the development and progression of radiographic osteoarthritis of the knee. Arthritis and rheumatism, 56(4), 1204-1211. https://doi.org/10.1002/art.22515

Cahuzac, J. P., Vardon, D., \& Sales de Gauzy, J. (1995). Development of the clinical tibiofemoral angle in normal adolescents. A study of 427 normal subjects from 10 to 16 years of age. Journal of bone and joint surgery, 77(5), 729-732. https://doi.org/10.1302/0301-620X.77B5.7559698

Chantraine, A. (1985). Knee joint in soccer players: osteoarthritis and axis deviation. Medicine and science in sports and exercise, 17(4), 434-439. https://doi.org/10.1249/00005768-198508000-00005

Cheema, J. I., Grissom, L. E., \& Harcke, H. T. (2003). Radiographic characteristics of lower-extremity bowing in children. Radiographics, 23(4), 871-880. https://doi.org/10.1148/rg.234025149

Cheng, J., Chan, P., Chiang, S., \& Hui, P. (1991). Angular and rotational profile of the lower limb in 2,630 Chinese children. Journal of pediatric orthopedics, 11(2), 154-161. https://doi.org/10.1097/01241398-199103000-00003

Colyn, W., Arnout, N., Verhaar, J. A., \& Bellemans, J. (2016). How does lower leg alignment differ between soccer players, other athletes, and non-athletic controls? Knee surgery, sports traumatology, arthroscopy, 24(11), 3619-3626. https://doi.org/10.1007/s00167-016-4348-y

Cowan, D. N., Jones, B. H., Frykman, P. N., Polly Jr, D. W., Harman, E. A., Rosenstein, R. M., \& Rosenstein, M. T. (1996). Lower limb morphology and risk of overuse injury among male infantry trainees. Medicine and science in sports and exercise, 28(8), 945-952. https://doi.org/10.1097/00005768-199608000-00002

Dvorak, J., \& Junge, A. (2000). Football injuries and physical symptoms. The American journal of sports medicine, 28(5_suppl), 3-9. https://doi.org/10.1177/28.suppl_5.s-3

Espandar, R., Mortazavi, S. M.-J., \& Baghdadi, T. (2010). Angular deformities of the lower limb in children. Asian 
journal of sports medicine, 1(1), 46-53. https://doi.org/10.5812/asjsm.34871

Espregueira-Mendes, J., van Dijk, C. N., Neyret, P., Cohen, M., Della Villa, S., Pereira, H., \& Oliveira, J. M. (2017). Injuries and Health Problems in Football. Berlin: Springer.

Faigenbaum, A. D. (2007). State of the art reviews: Resistance training for children and adolescents are there health outcomes? American journal of lifestyle medicine, 1(3), 190-200. https://doi.org/10.1177/1559827606296814

Flandry, F., \& Hommel, G. (2011). Normal anatomy and biomechanics of the knee. Sports medicine and arthroscopy review, 19(2), 82-92. https://doi.org/10.1097/JSA.0b013e318210c0aa

Horton, M. G., \& Hall, T. L. (1989). Quadriceps femoris muscle angle: normal values and relationships with gender and selected skeletal measures. Physical therapy, 69(11), 897-901. https://doi.org/10.1093/ptj/69.11.897

Işın, A. (2017). Futbola katılımın genu varum üzerine etkisi. (Yüksek Lisans), Akdeniz Üniversitesi Sağlık Bilimleri Enstitüsü, Antalya.

Jan van de Pol, G., Arnold, M. P., Verdonschot, N., \& van Kampen, A. (2009). Varus alignment leads to increased forces in the anterior cruciate ligament. The American journal of sports medicine, 37(3), 481-487. https://doi.org/10.1177/0363546508326715

Kishali, N. F., İmamoglu, O., Burmaoglu, G., Atan, T., \& Yildirim, K. (2004). Q-angle values of elite soccer and taekwondo athletes. The pain clinic, 16(1), 27-33. https://doi.org/10.1163/156856904322858675

Lathinghouse, L. H., \& Trimble, M. H. (2000). Effects of isometric quadriceps activation on the Q-angle in women before and after quadriceps exercise. Journal of orthopaedic and sports physical therapy, 30(4), 211-216. https://doi.org/10.2519/jospt.2000.30.4.211

Lewek, M. D., Rudolph, K. S., \& Snyder-Mackler, L. (2004). Control of frontal plane knee laxity during gait in patients with medial compartment knee osteoarthritis. Osteoarthritis and cartilage, 12(9), 745-751. https://doi.org/10.1016/j.joca.2004.05.005

Martin, W. E., \& Bridgmon, K. D. (2012). Quantitative and statistical research methods: From hypothesis to results (Vol. 42): John Wiley \& Sons.

McDermott, M., \& Freyne, P. (1983). Osteoarthrosis in runners with knee pain. British journal of sports medicine, 17(2), 84-87. https://doi.org/10.1136/bjsm.17.2.84

Ortiz, A., \& Micheo, W. (2011). Biomechanical evaluation of the athlete's knee: From basic science to clinical application. $P M \& R, 3(4), 365-371$. https://doi.org/10.1016/j.pmrj.2010.12.005

Park, S., Kong, Y.-S., Ko, Y.-M., Jang, G.-U., \& Park, J.-W. (2015). Differences in onset timing between the vastus medialis and lateralis during concentric knee contraction in individuals with genu varum or valgum. Journal of physical therapy science, 27(4), 1207-1210. https://doi.org/10.1589/jpts.27.1207

Rezende, L. F. M. d., Santos, M. d., Araújo, T. L., \& Matsudo, V. K. R. (2011). Does soccer practice stress the degrees of Genu Varo? Revista Brasileira de medicina do esporte, 17(5), 329-333. https://doi.org/10.1590/S1517-86922011000500007

Rossi, R., Bruzzone, M., Dettoni, F., \& Margheritini, F. (2011). Clinical examination of the knee. Orthopedic Sports Medicine (pp. 319-340): Springer. https://doi.org/10.1007/978-88-470-1702-3_25

Ruivo, R., Pezarat-Correia, P., Carita, A., \& Vaz, J. (2013). Reliability and validity of angular measures through the software for postural assessment. Postural Assessment Software. Rehabilitación, 47(4), 223-228. https://doi.org/10.1016/j.rh.2013.07.002

Shapiro, S. S., \& Wilk, M. B. (1965). An analysis of variance test for normality (complete samples). Biometrika, 52(3/4), 591-611. https://doi.org/10.1093/biomet/52.3-4.591

Tabachnick, B. G., \& Fidell, L. S. (2013). Using multivariate statistics (6 th ed.). Boston: Pearson.

Thijs, Y., Bellemans, J., Rombaut, L., \& Witvrouw, E. (2012). Is high-impact sports participation associated with bowlegs in adolescent boys? Medicine and science in sports and exercise, 44(6), 993-998. https://doi.org/10.1249/MSS.0b013e3182407ca0

Witvrouw, E., Danneels, L., Thijs, Y., Cambier, D., \& Bellemans, J. (2009). Does soccer participation lead to genu varum? Knee surgery, sports traumatology, arthroscopy, 17(4), 422-427. https://doi.org/10.1007/s00167-008-0710-z

\section{Copyrights}

Copyright for this article is retained by the author(s), with first publication rights granted to the journal.

This is an open-access article distributed under the terms and conditions of the Creative Commons Attribution license which permits unrestricted use, distribution, and reproduction in any medium, provided the original work is properly cited. 